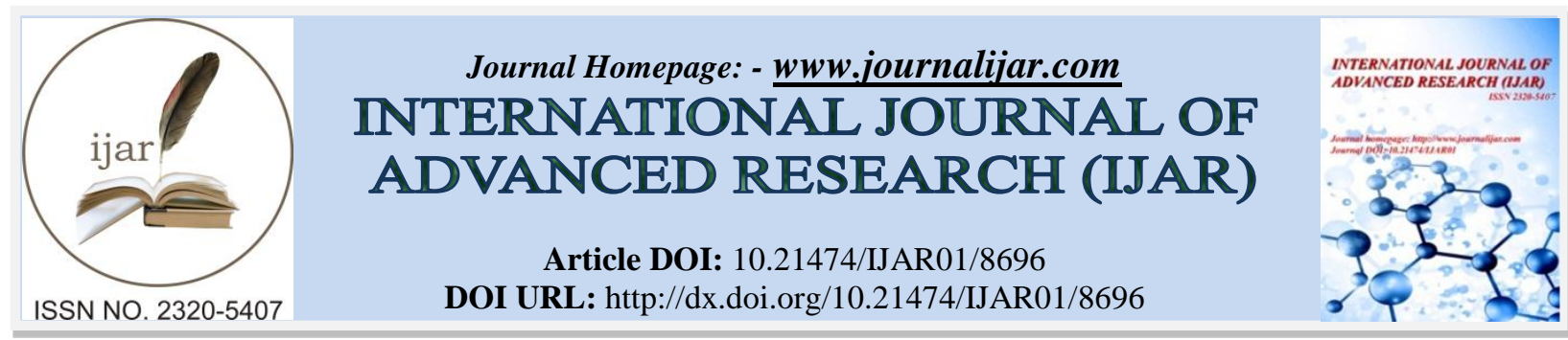

RESEARCH ARTICLE

\title{
OPTIMIZATION OF CULTURAL AND NUTRITIONAL PARAMETERS FOR ENHANCED PRODUCTION OF EXTRACELLULAR LACCASE FROM KALMUSIA SP RSO7.
}

Rashikha A Siddiqui ${ }^{1}$ and Dr. S. A. Peshwe ${ }^{2}$.

1. Research Scholar, Department of Microbiology, Government Institute of Science, Aurangabad, Maharashtra, India.

2. Associate Professor, Department of Microbiology, Government Institute of Science, Aurangabad, Maharashtra, India.

\section{Manuscript Info}

(.........................

Manuscript History

Received: 15 January 2019

Final Accepted: 17 February 2019

Published: March 2019

Key words:-

2,2-azino-bis(3-

ethylbenzthiazoline-6-sulfonic

acid) diammonium salt (ABTS),

Laccases, Kalmusia sp.RSO7,

Optimization, Gallic Acid.
Abstract

Laccases (benzenediol: oxygenoxidoreductases, EC 1.10.3.2). Laccases are effective biocatalysts for various biotechnological applications. Laccase production by fungal strain (RS07) isolated from litter soil has been investigated. The fungus developed grayish white cottony mass on potato dextrose agar and revealed thread like mycelium under microscope. The media components and cultural conditions for enhanced production of laccase were optimized by using "one variable at a time (OVAT)" in submerged fermentation. 2, 2-azino-bis (3ethylbenzthiazoline-6-sulfonic acid) diammonium salt (ABTS) was used as substrate for laccase. The cultural conditions viz., inoculum age of 5 days, incubation time of 7 days, at $25^{\circ} \mathrm{C}$ temperature with $\mathrm{pH} 10$ were found to be optimum. Such high $\mathrm{pH}$ for laccase production is exceptional with Kalmusia sp.RS07. In nutritional parameter optimization, Glucose and Tryptone were found to be the best carbon and nitrogen sources respectively. Addition of Gallic acid $(1 \mathrm{mM})$ induced laccase production upto 1.55 fold increased. This optimization process results in 5 fold increas with respect to laccase production.

Copy Right, IJAR, 2019,. All rights reserved.

\section{Introduction:-}

Laccases (benzenediol: oxygen oxidoreductases, EC 1.10.3.2).Multicopper Enzyme with broad range of substrate also known as blue copper oxidases. These multicopper oxidases catalyze the oxidation of various aromatic substances like diphenols, methoxy-substituted monophenols, aromatic amines. Molecular oxygen is the only prerequisite for oxidation unlike other peroxidases needs $\mathrm{H}_{2} \mathrm{O}_{2}$. (Thurston., 1994). These properties of laccase make it a versatile enzyme. Laccases were firstly isolated from Rhus vernicifere, Japanese lacquer tree (Yoshida, 1883). Laccases are found in plants, fungi and bacteria. Laccase activity has been demonstrated in many fungal species like ascomycetes, deutromycetes, and basidiomycetes. Well known laccase producer fungi includes Agaricus bisporus, Botrytis cinerea, Chaetomium thermophilum, Coprinus cinereus, Neurospora crassa, Phlebia radiate, Pleurotus ostreatus, Pycnoporus cinnabarinus, Trametes versicolor, and coriolus polyporus (Potti Ravindra Babu, 2012). Laccase also found in some bacteria such as Bacillus subtilis, Marinomonas mediterranea (Sanchez Amat A., 1997). Whereas actinomycets species includes Streptomyces griseus, S.lavendulae (Suzuki. T., 2003.). 
Concerning their use in the biotechnology area, fungal laccases have widespread applications, ranging from effluent decolourization and detoxification to pulp bleaching, removal of phenolics from wines, organic synthesis, biosensors, synthesis of complex medical compounds and dye transfer blocking functions in detergents and washing powders, many of which have been patented (Adinarayana Kunamneni, 2007). Owing to its vivid biotechnological applications, studies on laccase producing organisms have been intensified in the recent years and the optimization of laccase production from different microorganisms is being carried out by several researchers (Rajesh Kumar a, 2016). Carbon source, nitrogen source, $\mathrm{pH}$, temperature have great influence on laccase production in fungi. In present investigation various physical and nutritional parameters were studied to achieve maximum laccase production in submerged condition using ABTS as substrate for laccase.

\section{Materials and Methods:-}

All the chemicals were purchased from Hi media, Mumbai are of reagent grade.

\section{Fungal isolate:-}

Kalmusia sp.RSO7 isolated from litter soil sample was confirmed positive laccase activity by Guaiacol plate assay method. The fungal isolate was identified in the Genomebio technology Pvt. Ltd laboratory, Pune, Maharastra. The fungal isolate was maintained on Potato dextrose agar medium amended with $0.02 \%$ Guaiacol and incubated at $25 \pm 2^{\circ} \mathrm{C}$ for 7 days sub-cultured at regular intervals. The slants were stored at $4{ }^{\circ} \mathrm{C}$ in refrigerator.

\section{Media preparation and enzyme production:-}

$50 \mathrm{ml}$ of media 2 was inoculated with 2 mycelial plugs cut from the periphery of actively growing culture of $7 \mathrm{~mm}$ each in $250 \mathrm{ml}$ Erlenmeyer flask. The medium 2 contains the following ingredients $(\mathrm{g} / \mathrm{L})$ : Peptone-10, glucose-20, CuSO4-0.005, Malt extract-5 (Muhammad Shahbaz Aslam, 2012). Final pH was adjusted to 5.5. The flasks were incubated at $25^{\circ} \mathrm{C}$ for 7 days at $120 \mathrm{rpm}$. After incubation the production medium was filtered through muslin cloth to remove the biomass and centrifuged at $6000 \mathrm{rpm}$ for 15 minutes at $4^{\circ} \mathrm{C}$. The clear supernatant containing laccase enzyme was used as crude enzyme.

\section{Enzyme assays:}

The laccase activity from the culture media of Kalmusia sp. RSO7 was monitored by using substrate ABTS (Jung H, 2002) . $100 \mu \mathrm{l}$ of crude enzyme was mixed with $100 \mu \mathrm{l}$ of $10 \mathrm{mM}$ ABTS in $800 \mu \mathrm{l}$ of $50 \mathrm{mM}$ sodium acetate buffer $\left(\mathrm{pH} \mathrm{5)}\right.$ at $25^{\circ} \mathrm{C}$. With a spectrophotometer, measure the absorbance $A$ at $420 \mathrm{~nm}, 25^{\circ} \mathrm{C}$, during 1 to 10 minutes to monitor the oxidation of ABTS as formation of green colored product. Calculate the initial slope of the reaction $(\triangle A / \mathrm{min})$ in the linear part. If the slope is too steep $(>1 \Delta A / \mathrm{min})$, reduce the amount of sample $(100,50$ or $25 \mu \mathrm{l})$. The slope of the curve is then used to calculate the enzymatic activity in [U/l] ( $\mu \mathrm{mol}$ of ABTS oxidized par minute and per liter of sample), by the following equation:

$$
\begin{array}{rr}
\text { Activity }\left[\mu \mathrm{mol} \mathrm{min}^{-1} \mathrm{l}^{-1}\right]=\operatorname{slope}\left[\Delta \mathrm{Amin}^{-1}\right] 10^{6}\left[\mu \mathrm{mol} \mathrm{mol}^{-1}\right] \times & \mathrm{V}_{\text {tot }}[\mu \mathrm{l}] \\
\hline \varepsilon\left[\mathrm{mol}^{-1} \mathrm{lcm}^{-1}\right] 1[\mathrm{~cm}] & \mathrm{V}[\mu \mathrm{l}]
\end{array}
$$

With:

- $\varepsilon$ : the molar absorptivity (also called molar extinction coefficient), expressed in $\mathrm{M}^{-1} \cdot \mathrm{cm}^{-1}$, who

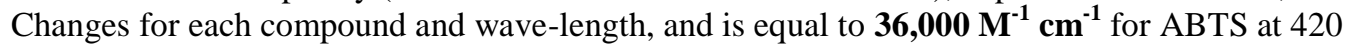

$\mathrm{nm}$

- 1: the optical pathlength, which is $\mathbf{1} \mathbf{~ c m}$ with these cuvettes

- $V:$ the volume of sample added (in $\mu$ l)

- Vtot: the final volume in the cuvette (usually $1000 \mu \mathrm{l}$ ) (Margot, 2015).

\section{Screening of different media:-}

Four different media, Potato Dextrose broth, Olga medium, Basal medium, Media 2, were screened for laccase production by Kalmusia sp. RSO7. In $250 \mathrm{ml}$ Erlenmeyer flasks containing $50 \mathrm{ml}$ of media were inoculated with 2 mycelial agar plugs and incubated at $25^{\circ} \mathrm{C}$ for 7 days at $120 \mathrm{rpm}$.

Optimization of submerged fermentation conditions for laccase production by OVAT process: -

All the fermentation experiments were carried out in $250 \mathrm{mlErlenmeyer} \mathrm{flasks} \mathrm{containing} 50 \mathrm{ml}$ of media 2. Laccase production by Kalmusia sp. RSO7 was first optimized by 'one variable at a time' (OVAT) approach to find out the most important factors affecting the fermentation process. 


\section{Time course:-}

The time course of laccase production by Kalmusia sp. RSO7 was monitored during submerged fermentation upto 14 days (Muhammad Shahbaz Aslam, 2012) and production rate was measured after every 24 hours of incubation in terms of laccase assay and dry weight of biomass. (Margot, 2015)

\section{Inoculum Age:-}

Kalmusia sp. RSO7 was grown on Potato Dextrose Agar for 3-7 days. Mycelial plugs were taken at 3, 4, 5, 6, and 7th day and used as inoculum for laccase production to evaluate optimum inoculum age for laccase production (Leticia I. RAMÍREZ-CAVAZOS, 2014).

\section{Influence of Incubation Temperature:-}

The effect of different temperatures was studied on laccase production .After inoculation; the flasks were incubated at different temperatures ranging from $20^{\circ} \mathrm{C}, 25^{\circ} \mathrm{C}, 30^{\circ} \mathrm{C}$ and $35^{\circ} \mathrm{C}$. After incubation laccase activity was determined according to standard assay procedures (Priyanka Ghosh, 2017).

\section{pH of media:-}

Laccase production with respect to $\mathrm{pH}$ was determined by inoculating the broth, set at different $\mathrm{pH}$, ranging from 4 to 12. (All adjustments were made before sterilization). After incubation laccase activity was determined according to standard assay procedures (Kusum Dhakar, 2013)

\section{Carbon Sources:-}

15 different carbon sources were used. The broth was distributed into $250 \mathrm{~mL}$ flasks containing $50 \mathrm{ml}$ medium 2 and $2 \%$ of each carbon sources were inoculated with 2 fungal mycelial plugs of $7 \mathrm{~mm}$ each, the flasks were incubated for 7 days at $25^{\circ} \mathrm{C}$ at $120 \mathrm{rpm}$.

\section{Nitrogen Sources:-}

14 different organic and inorganic nitrogen sources were used. The broth was distributed into $250 \mathrm{~mL}$ flasks containing $50 \mathrm{ml}$ medium 2 and $1 \%$ of each nitrogen sources were inoculated with 2 fungal mycelial plugs of $7 \mathrm{~mm}$ each, the flasks were incubated for 7 days at $25^{\circ} \mathrm{C}$ at $120 \mathrm{rpm}$.

\section{Inducer:-}

5 inducers namely Gallic acid $(1 \mathrm{mM})$, copper sulfate $(0.4 \mathrm{mM})$, tween $80(0.02 \mathrm{mM})$, DMP $(1 \mathrm{mM})$, guaiacol $(1 \mathrm{mM})$ were used to evaluate their influence on laccase production (Jose Renato P. Cavallazzi, 2005).

\section{Results and discussion:-}

Screening of different media:-

Different liquid media were used to determine optimum media composition for laccase production by Kalmusia $\mathrm{sp}$. RSO7 in submerged fermentation. Results obtained were summarized in fig. 1.0. Media2 showed highest laccase production (309.2 U/L) followed by Basal media 1(70.2 U/L). Whereas laccase production was observed in low quantity when grown in Potato Dextrose broth and Olga media. Laccase production by fungi has been shown to depend markedly on the composition of the culture medium, carbon, nitrogen content and inducer compounds (Ravankar, 2006) (Adejoye, 2010).

Fig. 1.0 


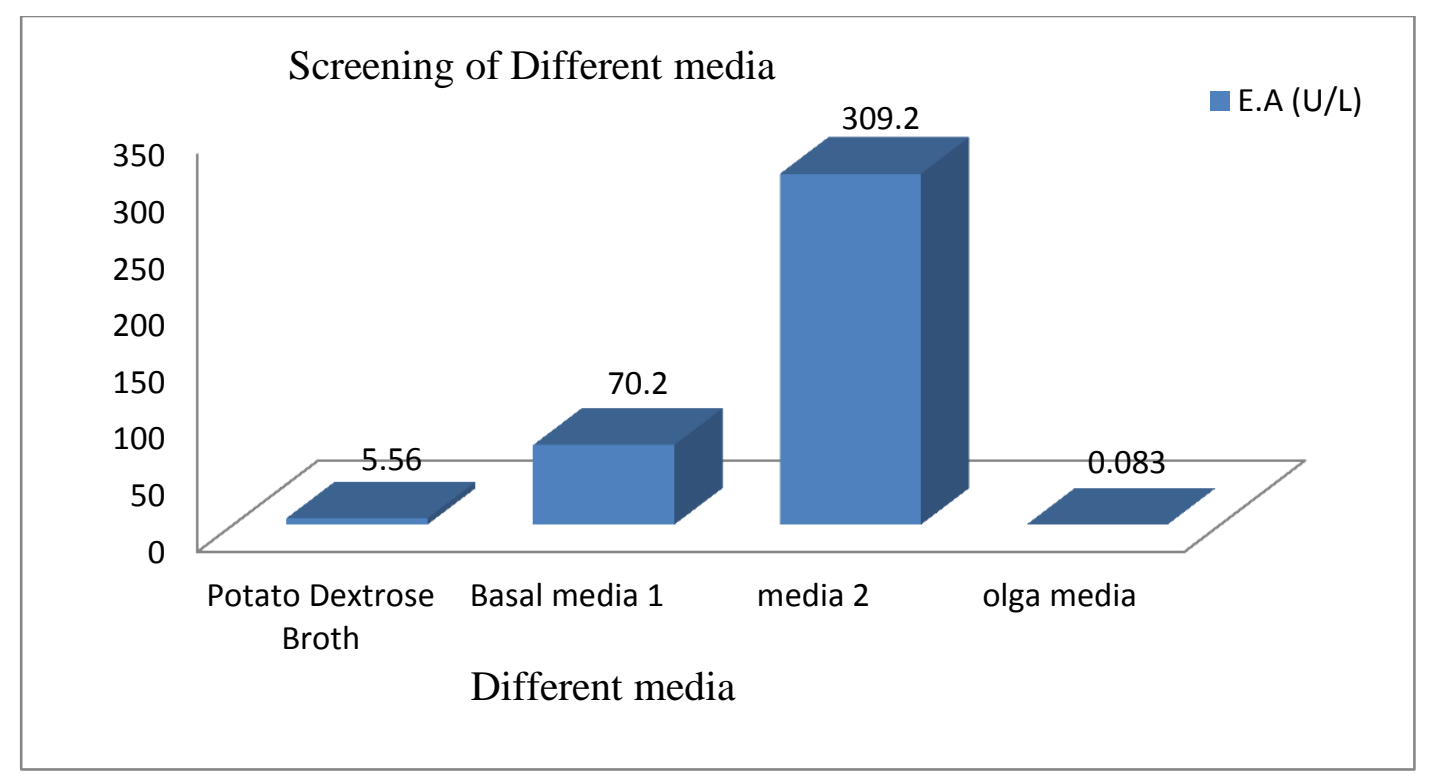

Optimization of submerged fermentation conditions for laccase production by OVAT process:

Time course:-

Fig. 2.0 shows the influence of time course study for laccase production in terms of enzyme activity and dry weight of fungal biomass. The maximum production of laccase was observed at $7^{\text {th }}$ day of incubation $(380.06 \mathrm{U} / \mathrm{L})$ during late exponential $\log$ phase. Laccases were generally produced during the secondary metabolism of fungi growing on natural substrate or in submerged culture (Buddolla Viswanath, 2014). 7 days incubation time is the shortest period to achieve maximum laccase production by fungi till date. Grzegorz Janusz et al reported 8 days of incubation period optimum for laccase production by Rhizoctonia particola (Grzegorz Janusz, 2006)

Fig. 2.0

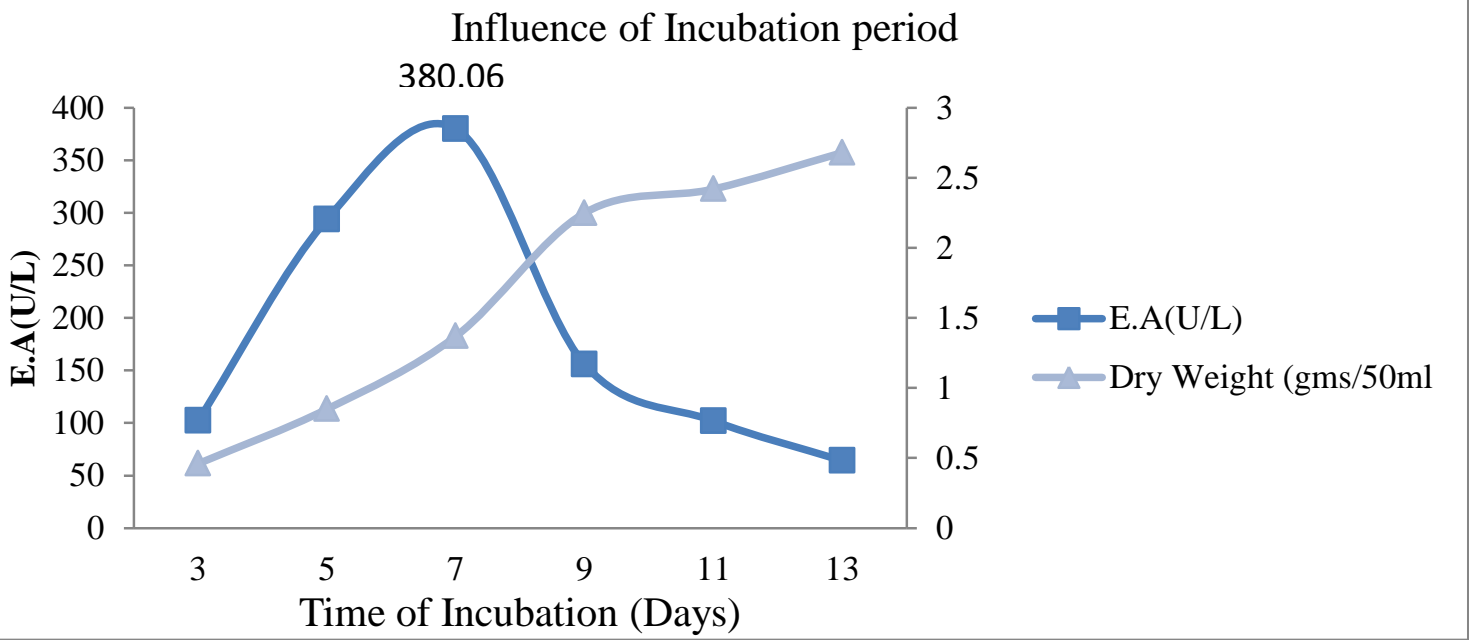

Inoculum Age:-

The data obtained from evaluation of inoculums age was summarized in fig. 3.0 revealed that when 5days old mycelia plugs were taken as inoculums the highest laccase production was achieved i.e (366.39 U/L). 
Fig.3.0.

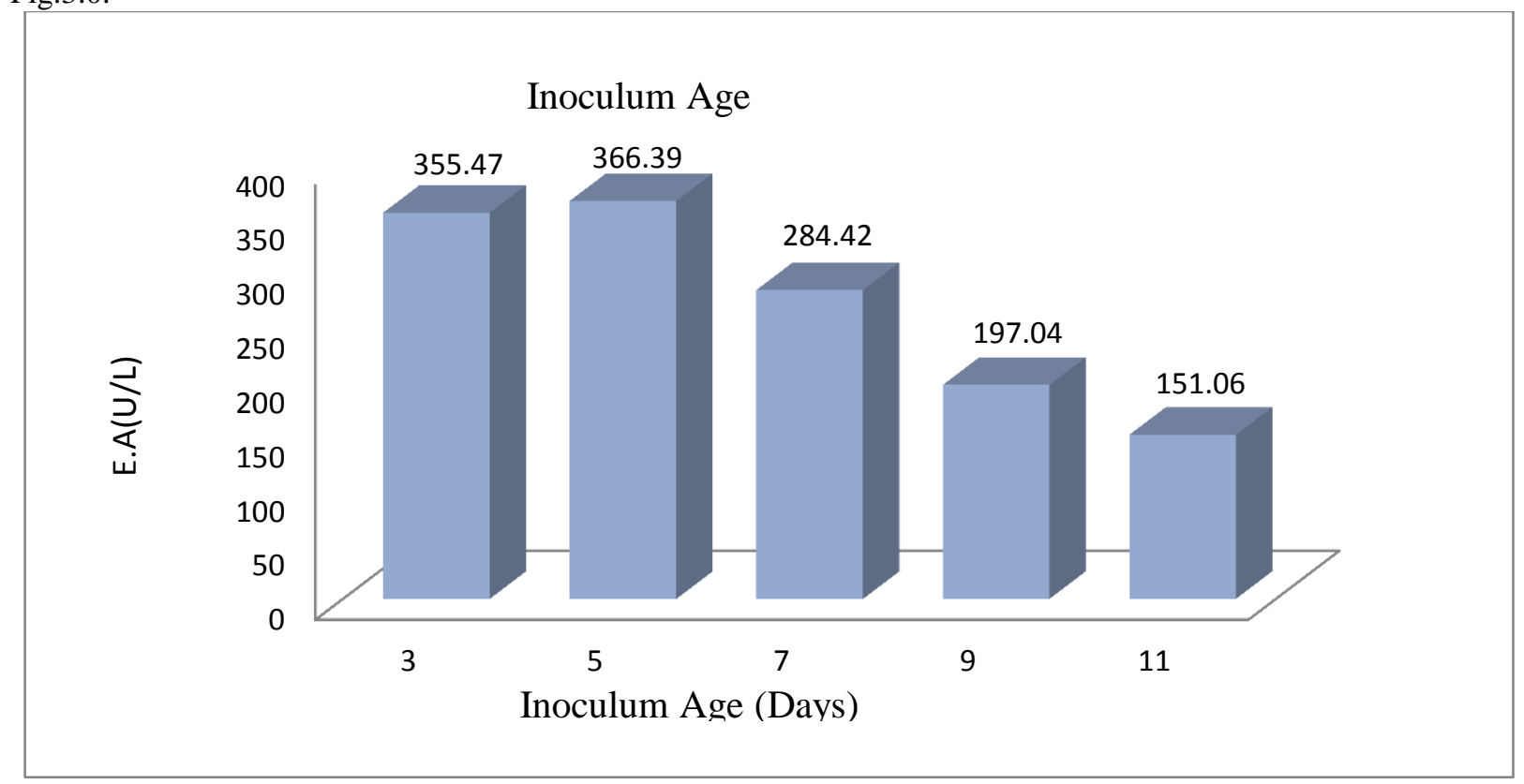

Incubation Temperature:-

In this experiment Kalmusia sp. RSO7 was grown at various degrees of temperature ranging from 20oc to 40oc. Kalmusia sp. RSO7 was able to grow and produce laccase within the range of incubation temperatures studied. The optimal temperature for fungal growth and laccase production was found to $25^{\circ} \mathrm{C}$ with $433.68 \mathrm{U} / \mathrm{L}$ laccase activity (fig. 4.0). Results also indicated that a gradual increase in temperature from $30^{\circ} \mathrm{C}$ to $35^{\circ} \mathrm{C}$ decreases the laccase production subsequently there was no enzyme activity detected at $40^{\circ} \mathrm{C}$. This can be interpreted by the alteration of cell membrane composition and stimulation of protein catabolism.

Fig.4.0

\section{Incubation temperature}

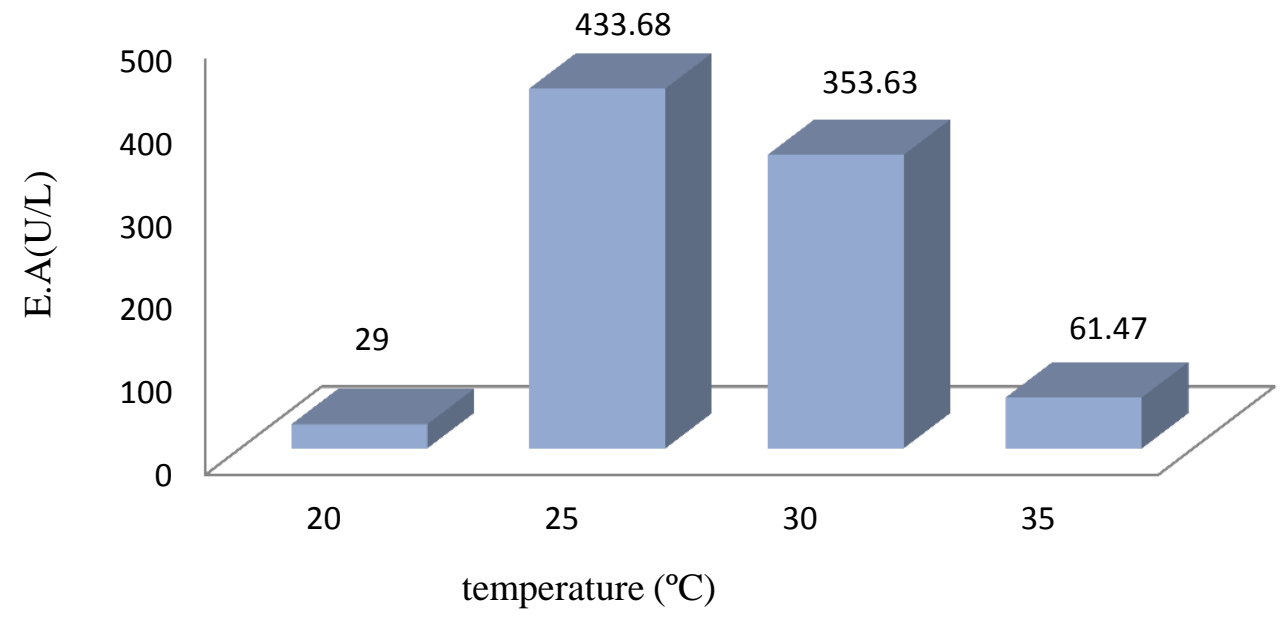




\section{pH of media:-}

A series of $\mathrm{pH}$ values ranging from 4.0 to 12.0 were studied in this experiment. Results obtained are shown in Fig.5.0 from which it is clear that maximal formation of Kalmusia sp. RSO7 laccase took place at pH 10 and laccase formation occurred at a broad range of $\mathrm{pH}$ values which is exceptional for this fungus, whereas considerably low levels of enzyme were obtained at $\mathrm{pH}$ 12. Janusz et al. have reported $\mathrm{pH} 7.5$, optimum for production of laccase by Rhizoctonia praticola, as an exceptional case (Grzegorz Janusz, 2006).

Fig. 5.0

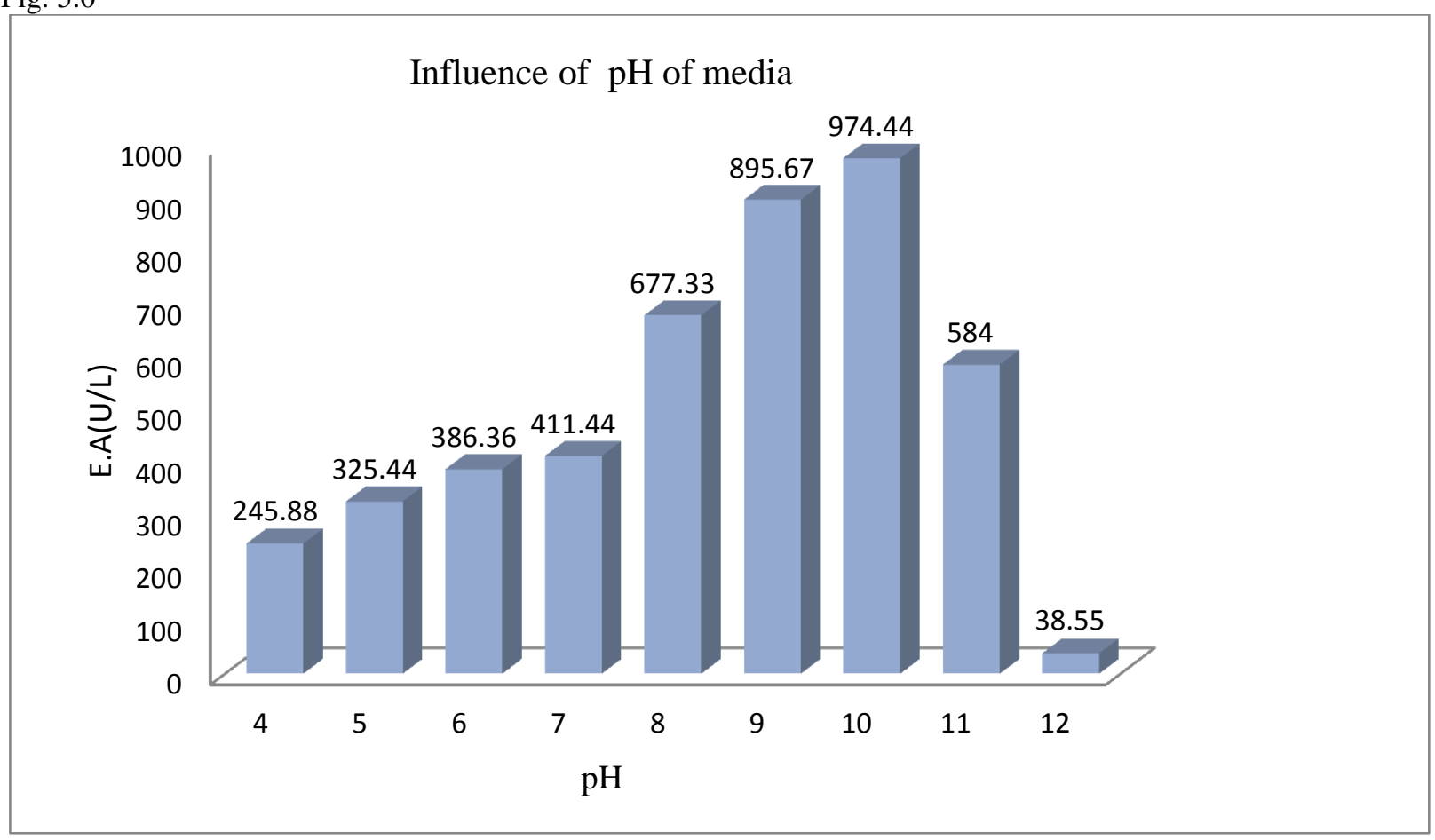

\section{Carbon Sources:-}

The conventional carbon sources play a important role in the production of laccase by fungi. For studying the effect of different carbon sources on the formation of laccase, monosaccharides (Arabinose, galactose, glucose, fructose, mannose, raffinose, ribose, xylose), disaccharides (lactose, sucrose), polysaccharides (cellulose and soluble starch), sugar alcohol like manitol, glycerol, Complex carbon source like malt extract, were used. Each carbon source was added at a concentration of $2 \%$ to the growing medium 2 as the main carbon source. The obtained results showed that glucose was found to be the best for laccase production. Results also indicate that laccase production took place with wide range of carbon source (Fig. 6.0). Similar results were found, maximum laccase production by $\mathrm{Pl}$. ostreatus HP-1 was obtained with 1\% (w/v) glucose containing medium (Patel, 2009). It was suggested that easily assimilable components such as glucose, allow for constitutive laccase production but repress its induction in several fungi (Bollag, 1984). 
Fig. 6.0

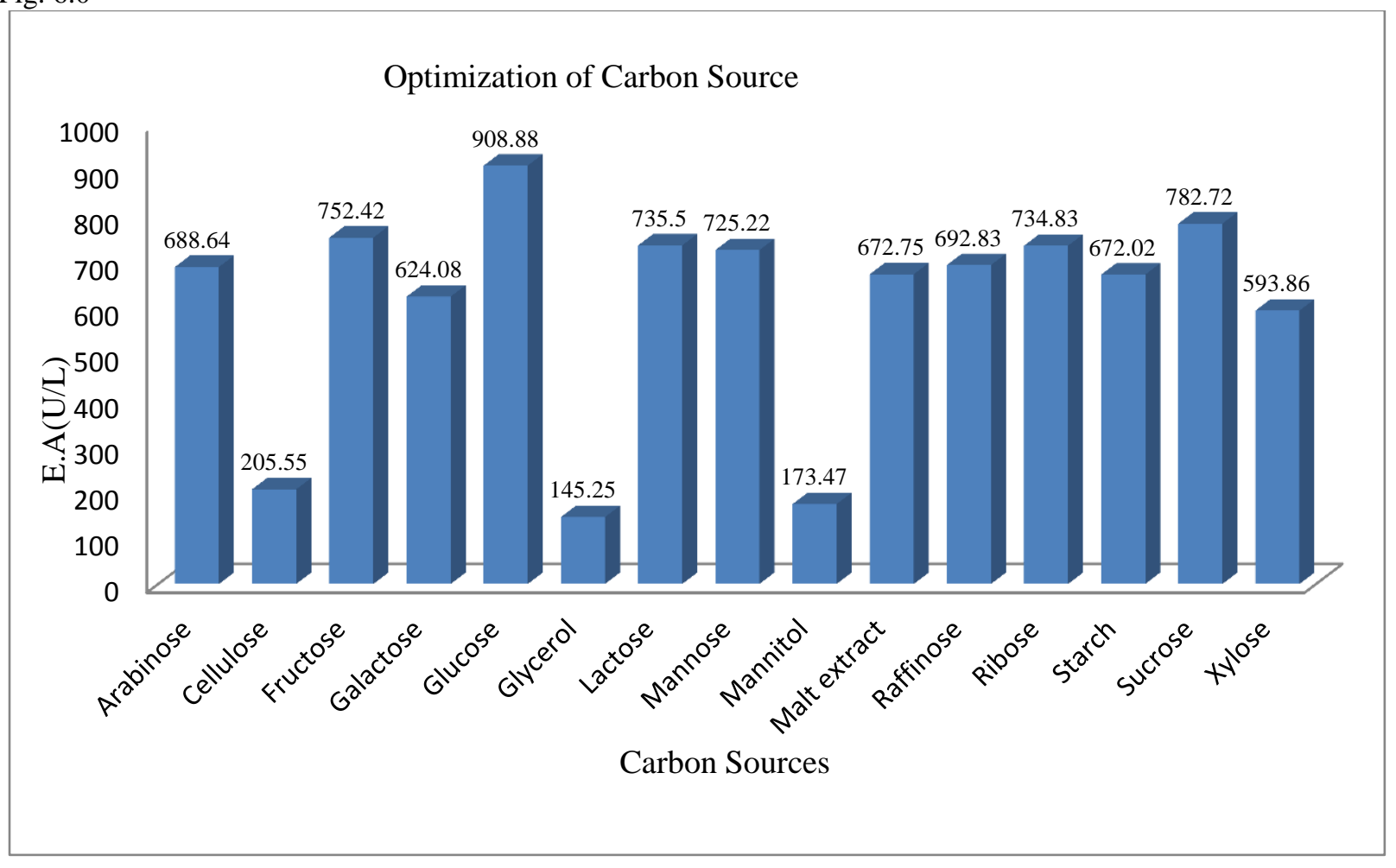

\section{Nitrogen Sources:-}

Various nitrogen compounds (ammonium nitrate, ammonium chloride, ammonium sulfate, di-ammonium phosphate, potassium nitrate as inorganic nitrogen sources, $\mathrm{L}(+)$ asparagine, L-alanine, beef extract, casein, egg albumin, peptone, meat extract, tryptone,yeast extract as organic nitrogen sources were added separately to the culture medium 2 at $1 \%$ level. The highest level of enzyme production was obtained with tryptone (960.87U/L) followed by meat extract $(304.17 \mathrm{U} / \mathrm{L})$, peptone $(298.08 \mathrm{U} / \mathrm{L})$. The rest of nitrogen sources also gave considerable amounts of laccase except ammonium sulfate, ammonium nitrate, alanine which gave the lowest enzyme activity as shown in fig.7.0. 
Fig. 7.0

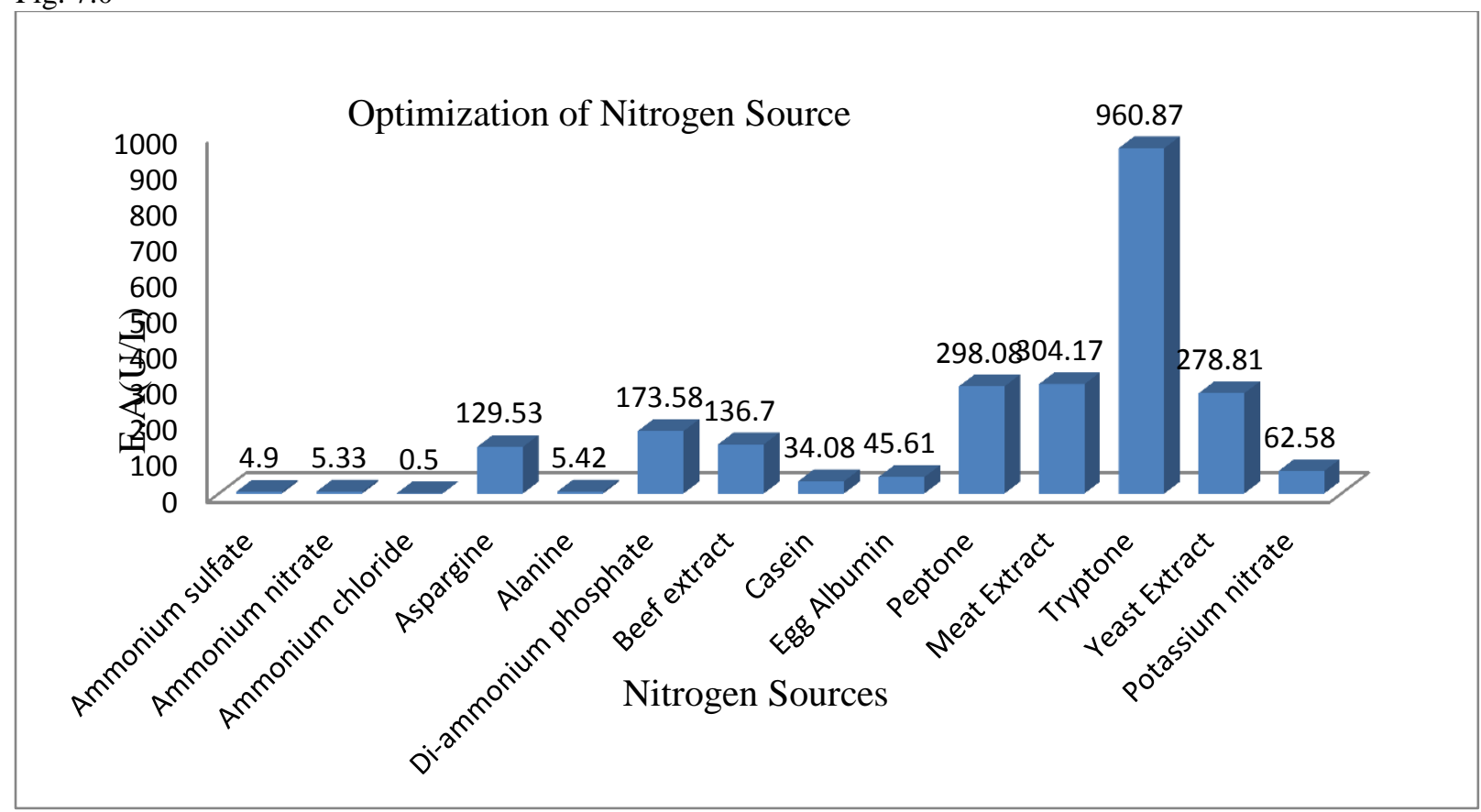

\section{Effect of Inducer:-}

5 inducers namely Gallic acid $(1 \mathrm{mM})$, copper sulfate $(0.4 \mathrm{mM})$, tween $80(0.02 \mathrm{mM})$, DMP $(1 \mathrm{mM})$, guaiacol $(1 \mathrm{mM})$ were used to evaluate their effect on laccase production by Kalmusia sp. RS07. Gallic acid showed maximum production of laccase with (1447.55U/L) where as tween-80 showed inhibitory effect on growth of fungi. Other compoundes showed activity slightly lower than observed in control flask (fig.8.0)

Fig. 8.0.

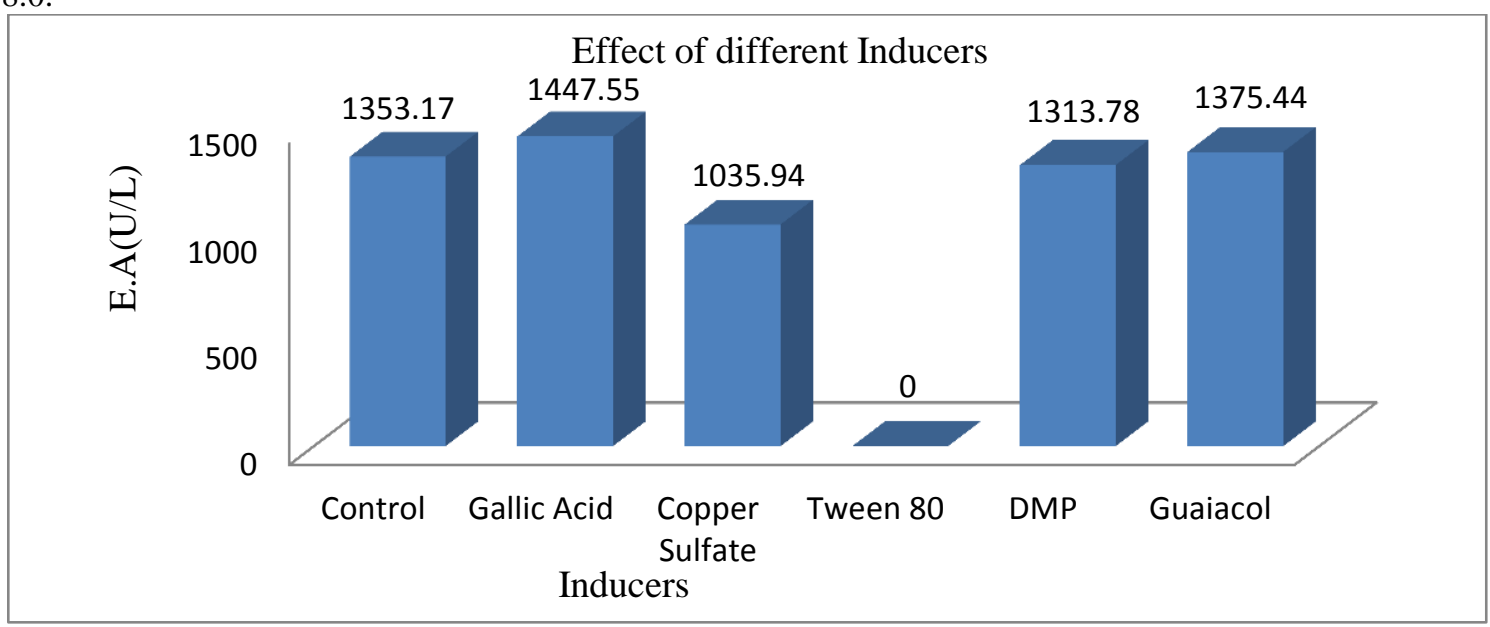

\section{Conclusion:-}

RS07 was found to be the potent laccase producer and identified as Kalmusia sp RS07.The media components and cultural conditions for enhanced laccase were optimized by using one variable at a time in submerged fermentation. The cultural conditions viz, inoculum age of 5 days, incubation time of 7 days, at $25^{\circ} \mathrm{C}$ temperature with $\mathrm{pH} 10$ were found to be optimum. Such high $\mathrm{pH}$ for laccase production is exceptional with Kalmusia sp.RS07. In nutritional parameter optimization experiment glucose and Tryptone were found to be the best carbon and nitrogen sources respectively. Addition of Gallic acid $(1 \mathrm{mM})$ induced laccase production and production was increased upto 1.55 fold. The overall optimization process results in 5 fold increase in laccase production. 


\section{References:-}

1. Adejoye, O. F. (2010). Effect of cultural conditions on biomass and laccase production in submerged medium by Schizophyllum commune (Fries), a Nigerian edible mushroom. EJEAF che, 9(3) , 600-609.

2. Adinarayana Kunamneni, A. B. (2007). Fungal laccase-a versatile enzyme for biotechnological application. Current Research and Educational Topics and Trends in Applied Microbiology, 233-242.

3. Bollag, J. L. (1984). Comparative studies of extracellular fungal laccases. Appl. Environ. Microbiol. 48 , 849854.

4. Buddolla Viswanath, B. R. (2014). Fungal Laccases and Their Applications in Bioremediation. Enzyme Research, 1-21.

5. Grzegorz Janusz, J. R. (2006). Effect of Culture conditions on production of extracellular laccase by Rhizoctonia particola. Polish Journal of Microbiology, volume 55 No. 4 , 309-319.

6. Jose Renato P. Cavallazzi, C. M. (2005). Screening of inducers for laccase production by Lentinula edodes in liquid medium. Brazilian Journal of Microbiology 36 , 383-387.

7. Jung H, X. F. (2002). Purification and characterization of laccase from wood-degrading fungus Trichophyton rubrum LKY-7. Enzyme Microb Technol 30:161-168, 30:161-168.

8. Kusum Dhakar, A. P. (2013). Laccase Production from a temperature and $\mathrm{pH}$ tolerant fungal strain of Trametes hirsuta (MTCC 11397). Enzyme Research, 1-9.

9. Leticia I. Ramirez-Cavazos, C. J.-C. (2014). Enhanced production of thermostable laccase from a native strain of Pycnoporus sanguineus using central composite design. J. Zhejiang Univ-Sci (Biomed \& Biotechnol) 15(4), 343-352.

10. Margot J, M. J. (2013). Influence of treatment conditions on oxidation of micropollutants by Trametes versicolor laccase. N Biotechnol 30(6) , 803-813.

11. Margot, J. (2015, feb). Micropollutant removal from municiple wastewater-from conventional treatments to advanced biological processes. Doctoral thesis . Switzerland: EPFL university.

12. Muhammad Shahbaz Aslam, A. A. (2012). Identification, Purification and Characterization of a Novel Extracellular Laccase from Cladosporium Cladosporioides. Biotechnology \& Biotechnological Equipmen , 26:6, 3345-3350.

13. Patel, H. G. (2009). Effect of different cultural conditions and inducers on production of laccase by a basidiomycete fungal isolate Pleurotus HP-1 under solid state fermentation . Bioresour 4(1), 268-284.

14. Potti Ravindra Babu, R. P. (2012). Occurrences, Physical and Biochemical Properties of Laccase. Universal Journal of Environmental Research and Technology Volume 2, Issue 1: 1-13 , 1-13.

15. Priyanka Ghosh, U. G. (2017). Statistical optimization of laccase by Aspergillus flavus PUF5 through submerged fermentation using agro-waste as cheap substrate. Acta Biologica Szegediensis volume 61, 25-33.

16. Rajesh Kumar a, J. K. (2016). Optimization of laccase production from Aspergillus flavus by design of experiment technique: Partial purification and characterization. Journal of Genetic Engineering and Biotechnolgy, 14, 125-131.

17. Ravankar, M. L. (2006). Enhanced production of laccase using a new isolate of white-rot fungus WR-1. Proc. Biochem. 41, 581-588.

18. Sanchez Amat A., S. (1997). A pluripotent polyphenol oxidase from the melanogenic marine Alteromonas Sp. Shares catalytic capabilities of Tyrosinases \& Laccases. Biochem.Biophysics.240. , 787-792.

19. Suzuki. T., E. K. (2003.). A thermostable Laccase from Streptomyces lavendulae REN-7: Purification, characterization, Nucleotide Sequence \& Expression. Biosci. Biotechnol. Biochem.67. , 2167-2175.

20. Thurston., C. F. (1994). The structure and function of fungal laccase. Microbiology 140, 19-26.

21. Yoshida. (1883). Chemistry of lacquer (urushi). J Chem Soc.; 43 , 472-486. 